\title{
A CONTROLLED INVESTIGATION OF ARTANE IN CEREBRAL PALSY
}

\author{
BY \\ JOHN LORBER \\ From the Department of Child Health, The University of Sheffield
}

(RECEIVED FOR PUBLICATION DECEMBER 6, 1954)

Drugs have played little part in the treatment of cerebral palsy and none so far have been proved to be of much value. Recently, a group of drugs, trihexyphenidyl and its near analogues, e.g. 'parpanit' and 'artane', have been shown to be useful in Parkinsonism and allied conditions affecting the extrapyramidal motor system. It was considered that these drugs might be of some value in the treatment of infantile cerebral palsy, especially in children with athetosis. It was hoped, however, that some children with the spastic form of cerebral palsy might also benefit, because the lesion is rarely confined to the pyramidal system. When this investigation was planned, no reference had been found to the use of these drugs in cerebral palsy. Corner (1952) demonstrated their favourable effect on two cases of torsion spasm. A little later Melin and Herrlin (1952) reported that they used 'parpanit' in nine cases of cerebral palsy without effect, but 'artane' was successful in relieving increased muscle tone in five cases and was beneficial in one case of pronounced athetosis. Side-effects were minimal. The dose employed was $0.5 \mathrm{mg}$. gradually increasing to $4 \mathrm{mg}$. daily.

\section{Present Investigation}

In this investigation trihexyphenidyl ('artane') was used. It seemed evident that considerable difficulties would be encountered in the assessment of its effects in cerebral palsy unless precautions were taken to eliminate subjective bias. The plan of the investigation was as follows.

Material and Treatment. Patients suffering from severe congenital cerebral palsy were selected for the investigation and were divided into two groups. One group of 17 patients consisted of 'spastics', with paraplegia, hemiplegia or quadriplegia. The second group consisted of 11 patients with athetosis (including seven cases of kernikterus). Most of these patients had been attending our out-patient clinic and physiotherapy department and the extent of their disability and their rate of progress without treatment with drugs was known. New patients were not included in the investigation until they had received at least two months of intensive physiotherapy.

To ensure an adequate method of control, we requested the makers of 'artane' to supply us with two sets of identical-looking tablets labelled A and $B$, one being 'artane', and the other an inert substance. Neither the investigator nor the hospital pharmacist knew which were the real 'artane' tablets. The pharmacist was given two sets of envelopes, one for 'spastics' and another for 'athetoids'. Both batches of envelopes contained chits labelled A or B. When a patient was accepted for the investigation 'artane' was prescribed, and the prescription was marked 'spastic' or 'athetoid'. The pharmacist then drew an envelope, and, in accordance with the direction which it contained, she dispensed tablets A or B, keeping the appropriate records in a book. This book was not seen by me until after the analysis was completed.

The dose was gradually increased during the three months from $1 \mathrm{mg}$. to a maximum of $10 \mathrm{mg}$. daily, according to tolerance. At the end of three months the child's condition was reassessed and 'reverse artane' was prescribed for the next three months, a child who had had A tablets receiving $B$ tablets and vice versa. The children were then observed for another three months without any drugs* at all.

The parents were told that the children were to receive a new drug which might or might not be of benefit and they were asked to take particular note of the children's general condition, behaviour, and physical and mental progress during treatment. They were also asked to note untoward symptoms. They were not aware that two sorts of tablets were to be used or that at the end of three months the drugs would be different.

Physiotherapy was continued during the investigation, but no other drug was given.*

\footnotetext{
* Except for anticonvulsants in those subject to fits.
} 
The children were examined by the physiotherapist and by me at the beginning of the investigation and at intervals during and after it, so that their disability could be assessed. When the analysis of the findings was complete, the identity of tablets $A$ and $B$ was determined from the makers.

\section{Results}

Spastics. No objective difference in the physical signs could be detected during or after treatment in any patient.

Of eight mothers whose children received 'artane' first, two reported that there was no change, two that there had been slight improvement, three that improvement had been appreciable and one that improvement was marked. Of the nine who received the control tablets first, one did not improve, six improved slightly, and two improved greatly. The improvement lay in an increased alertness and activity and a loosening up of the muscles. None of the children who improved on 'artane' relapsed while receiving the control tablets or during subsequent observation, and none of the children who improved on the control tablets improved more while receiving 'artane' later. One child who improved on the control tablets 'relapsed' while receiving 'artane'. One child on the control tablets and another on 'artane' complained of repeated vomiting.

It was clear that there was no evidence that 'artane', as used in this trial, was of value in these cases.

Athetoids. Many athetoids responded to the treatment much more dramatically than the spastics.

The condition of three children was thought by their parents to be unchanged throughout the trial. Two children were thought to have improved slightly while receiving the control tablets and also while receiving the 'artane'. The improvement continued after the treatment had been discontinued. None of these children showed objective improvement and none had toxic symptoms.

Of the remaining six patients, five had control tablets first. A boy of 13 was said by his mother to have improved miraculously, becoming much livelier and attempting with success tasks, such as dressing, playing or feeding himself, which he had never undertaken before. He showed no objective improvement or lessening of the athetosis. After the end of three months he had no drugs for a few days and he returned to his previous inactive state. He was then given 'artane' and he immediately 'went to pieces'. He became extremely unsteady, was constantly falling and could do much less than before. After two weeks his treatment had to be discontinued and he returned to the condition he was in before the trial started.

Another child, a boy aged 5, was said to have improved in many respects while on the control tablets. He was livelier, but fell more often. There was a dramatic deterioration in his condition when changed to 'artane'. He lost his balance completely and could no longer walk. Treatment had to be interrupted. He then rapidly regained his previous state and has remained much the same since.

The third of these children, a boy of 7 , was described as 'grand' while receiving the control tablets and was much steadier. Owing to intercurrent illnesses the experiment could not be concluded.

The fourth, a girl of 3 years, showed slow steady improvement while on the control tablets, but immediately after she started taking 'artane' she became limp, was unable to stand, was very ataxic and the athetosis became more severe. The mother persisted with the tablets in spite of these toxic symptoms for two weeks, but then treatment was stopped and the child made an immediate recovery.

The fifth child, a boy of 12, did not exhibit any change in his condition while on the control tablets, but soon after he started taking 'artane' he also became grossly ataxic, could no longer stand and had severe loss of tone. In addition he had several fits, although he had not been subject to them before. Treatment was stopped and he immediately recovered.

Finally, a girl of 8 with kernikterus started with 'artane' tablets. She exhibited the same toxic symptoms as the preceding cases. The athetosis became much worse and she became grossly ataxic. She had previously been subject to fits, but her fits increased in number and changed their character. She now had severe myoclonic attacks without loss of consciousness. Treatment was stopped and she quickly regained her previous condition.

It should be emphasized that these severe and uniform toxic symptoms in five children all occurred at the beginning of 'artane' treatment when the dose was small, 1-2 mg. daily.

\section{Summary and Conclusions}

'Artane' was used in a controlled therapeutic trial in congenital cerebral palsy. Most of the 17 'spastic' children improved while on treatment, irrespective of whether they received 'artane' or control tablets. They all maintained the improvement after the conclusion of treatment.

Five of 11 athetoids exhibited no significant change in their condition whether on 'artane' or on the 
control tablets. Two of the remaining six were greatly improved while on the control tablets, two were moderately improved and one remained the same. The sixth did not receive the control tablets. Five of these six patients exhibited dramatic toxic effects while on small doses of 'artane', consisting of loss of balance, hypotonia, increased athetosis and two developed fits. Treatment with 'artane' had to be discontinued in these five. None derived benefit from 'artane' in the dosage employed.
It is a pleasure to acknowledge the cooperation of Dr. A. T. Mennie, Medical Director of Lederle Laboratories, who kindly provided 'artane' and the control tablets for this investigation.

I wish to thank Professor R. S. Illingworth for his criticism, Professor E. J. Wayne, Dr. T. Colver and Dr. R. R. Gordon for access to their cases; Miss L. M. Green, Senior Physiotherapist, and Miss C. I. Crawford, Chief Pharmacist, for their cooperation in this trial.

REFERENCES

Corner, B. D. (1952). Proc. roy. Soc. Med., 45, 451. Melin, K.-A. and Herrlin, K.-M. (1952). Acta paediat., Uppsala. 41, 495 . 